TOC graphic

17

18 Key words: DFT, Oxygen Reduction Reaction, XPS simulation, water/Pt interfaces, hydrated OH 19

\section{Characterization of oxygenated species at water/Pt(111) interfaces from DFT energetics and XPS simulations}

Zhenhua Zeng and Jeffrey Greeley*

School of Chemical Engineering, Purdue University, West Lafayette, Indiana 47907, USA

*jgreeley@purdue.edu
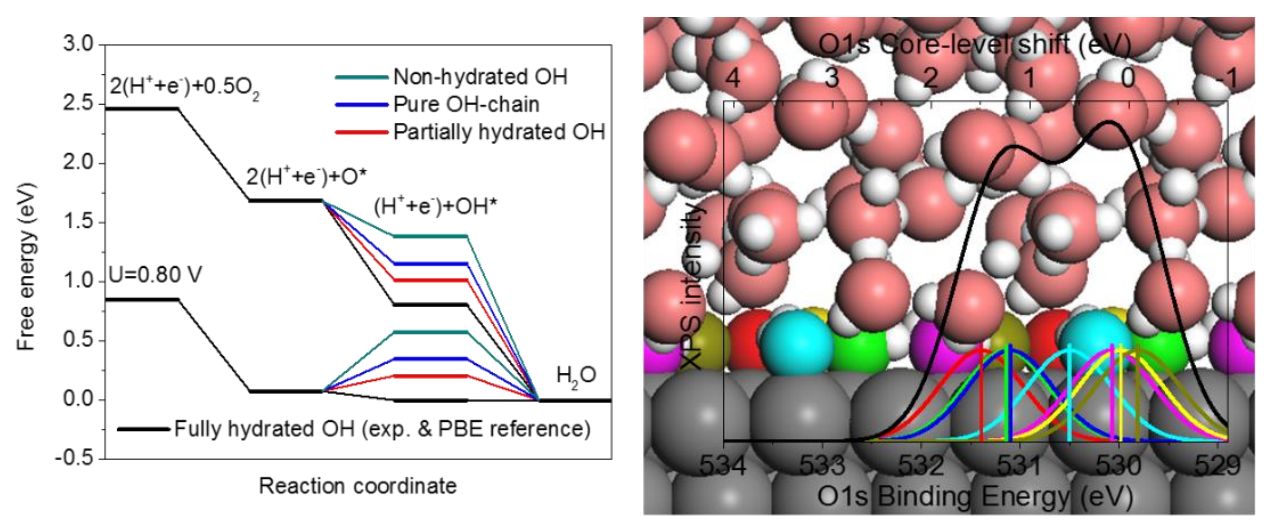
Determining the atomic-scale structure of oxygenated species at water/Pt(111) significant, long-term challenge for both experimentalists and theorists. Numerous techniques have elucidated important information about this system, but significant uncertainties relating to the structure and hydration state of adsorbed oxygenated species remain. To resolve some of these questions, an approach based on careful calibration of Density Functional Theory (DFT)determined energetics, as well as detailed simulation of X-ray Photoelectron Spectroscopy (XPS) signatures, is developed. The combined energetic and XPS analysis of various oxygenated species demonstrates that non-hydrated $\mathrm{OH}$, which has been suggested, by analysis of O1s corelevel binding data from state-of-the-art XPS studies, to be an abundant surface species at water/Pt(111) interfaces during ORR, is in fact unlikely to exist at potentials relevant to ORR, although it might be found in other conditions. The $\mathrm{OH}$ is more likely present in a fully hydrated state, and the experimentally observed features can be assigned to other oxygen arrangements. This insight about the nature of $\mathrm{OH}$ binding at water-Pt interfaces has implications not only for the general understanding of electrified water/Pt interfaces, but also for the design of ORR catalysts with improved performance on the basis of first principles calculations.

\section{Introduction}

The performance of low temperature fuel cells is well known to be limited by the high overpotentials of the oxygen reduction reaction (ORR) on platinum cathodes, as has been extensively discussed in literature and in several papers in the present issue.[1-5] Under electrochemical ORR conditions at intermediate potentials, $\mathrm{OH}$ is generally believed to be the most abundant surface intermediate on platinum, and weakening of the $\mathrm{OH}$ binding to platinum has been proposed to be a key requirement to improve the ORR activity of this catalyst.[6-8] However, the nature of $\mathrm{OH}$ binding, and the degree of $\mathrm{OH}$ hydration under ORR-relevant conditions, is still under debate, and the resulting uncertainty has implications not only for the detailed understanding of the catalytic mechanism on platinum but also for the accuracy of catalyst design efforts.

$\mathrm{OH}$ species have been proposed to exist in a variety of hydration environments, and significant theoretical and experimental work has been undertaken to elucidate details of the corresponding structures on idealized $\mathrm{Pt}(111)$ electrode surfaces. Thermodynamic analyses based on density functional theory (DFT) calculations have been employed to distinguish the relative stability of $\mathrm{OH}$ moieties in these different environments. It has been reported, for example, that isolated/non-hydrated hydroxyl groups on $\mathrm{Pt}(111)$ are not stable and either preferentially form $\mathrm{OH}$ chains or become hydrated in the presence of water, where hydrogen bonds stabilize the $\mathrm{OH}$ species.[9-11] Indeed, the solvation energy of fully hydrated $\mathrm{OH}$ has been estimated to be about $50 \mathrm{~kJ} / \mathrm{mol},[6,9]$ and hydrated $\mathrm{OH}$ has been suggested, in several studies, to be the most abundant species under conditions relevant to the ORR.[6, 8-10, 12-14] Pioneering first principles-based Monte Carlo simulations of Linear Sweep Voltammetry, on the other hand, have implied that non-hydrated $\mathrm{OH}$ species may actually exist at significant coverages under these conditions due to a de-wetting effect caused by adsorbed atomic 
oxygen.[7, 15] We note, however, that the delicate interactions between adsorbed hydroxyl, atomic oxygen, and water molecules in the complex electrochemical double layer make such simulations challenging, $[16,17]$ and it is non-trivial to extract the absolute and relative stabilities of these species on platinum surfaces. As a consequence, the complete structure of cyclic voltammograms on $\mathrm{Pt}(111)$ in the ORR-relevant potential range of $0.8 \mathrm{~V}$ to $1.2 \mathrm{~V}$ vs RHE, which is generally thought to be associated with the phase transition between adsorbed $\mathrm{OH}$ and adsorbed $\mathrm{O}$, has not, to our knowledge, been fully described in any computational study. $[1,7$, $15,18,19]$

Several fundamental surface science studies have recently determined the binding energies of atomic oxygen and hydrated $\mathrm{OH}$ on $\mathrm{Pt}(111)$ surfaces under well-controlled conditions.[11, 20-22] However, such techniques are not easily applied to more complex electrochemical environments with substantial amounts of adsorbed or near-surface water. In contrast, core-level binding energies generated by XPS have been employed to identify similar species under both UHV[23-30] and in-situ electrocatalytic conditions.[7, 31-37] Of particular relevance for developing fundamental understanding of the ORR, O1s binding energies have been fit and assigned to various oxygenated species, including adsorbed $0,[7,23,24,30]$ multilayer $\mathrm{H}_{2} \mathrm{O},[7,23,24,30]$ adsorbed $\mathrm{H}_{2} \mathrm{O},[7,23-25,30]$ hydrated $\mathrm{OH},[7,23,24,30]$ and nonhydrated $\mathrm{OH}[7]$ at the water/Pt interface. Since the core-level binding energies are very sensitive to the local environment, every oxygenated species with different local structure has distinct binding energies, providing the tantalizing possibility of rigorously determining the structure and hydration environment of $\mathrm{OH}$. However, this very complexity makes the fitting and assignment of XPS peaks very demanding, and detailed theoretical simulations of XPS signatures can assist in the deconvolution of these signatures. [23, 25, 38-46]

In the present paper, we combine DFT calculations, energetic analyses, ab-initio molecular dynamics simulations (AIMD), and XPS simulations to investigate the nature of $\mathrm{OH}$ binding at the water/Pt(111) interface. Using well-defined water bilayers, mixed $\mathrm{H}_{2} \mathrm{O}-\mathrm{OH}$ overlayers, and known structures of oxygenated intermediates as examples, we first benchmark the performance of different density functionals for binding energy determinations and XPS simulations. Next, based on combined thermodynamic and XPS simulations, we analyze the detailed structure of oxygenated species in more complicated hydration environments at water/Pt interfaces. We propose an interpretation of the state of $\mathrm{OH}$ at ORR-relevant potentials that accounts for available theoretical and experimental results, and we discuss the implications of the results for both fundamental studies of oxygen reduction on well-defined platinum surfaces and for the identification of improved ORR catalysts for low temperature fuel cells.

\section{Computational details}

Periodic DFT calculations and AIMD simulations are performed with the Vienna Ab-Initio Simulation Package, VASP,[47, 48] using the projector augmented wave (PAW) method,[49-51] unless otherwise specified. Self-consistent total energies are evaluated using both the exchange-correlation functionals PBE[52] and RPBE[53] and the van der Waals density functionals (vdW-DF) optPBE[54] and BEEF[55]. For cell shape and volume relaxations of bulk ice, a cutoff energy of $500 \mathrm{eV}$ is used for the planewave expansion. A cutoff energy of $400 \mathrm{eV}$ is used for the subsequent total energy calculations of Ice without cell shape and volume 
relaxations, as well as for all of the other systems studied. For ice $\mathrm{XI}$, the hydrogen-ordered form of Ih with space group $\mathrm{Cmc2}_{1}$ and $8 \mathrm{H}_{2} \mathrm{O}$ molecules per super cell,[56, 57] Brillouin zone integration with $(7 \times 4 \times 4)$ Monkhorst-Pack k-point grids is performed. For the face centered cubic (fcc) Pt bulk unit cell, $(14 \times 14 \times 14)$ k-point grids are used, while k-point grids of equivalent or higher density are used for the surface calculations. The geometries are optimized until the maximum atomic forces are smaller than $0.02 \mathrm{eV} / \AA$, and a total energy convergence of $10^{-5} \mathrm{eV}$ in the electronic self-consistent field loop is employed. The Pt lattice constants are calculated to be $3.98 \AA, 4.00 \AA, 4.00 \AA$ and $4.03 \AA$ with PBE, RPBE, optPBE and BEEF, respectively, by minimizing the cell stress with the above parameters. For the calculations of gas phase molecules, an orthorhombic box (14 $\mathrm{A} \times 15 \AA \mathrm{A} \times 16 \AA$ ) and a single k-point $(0.25,0.25,0.25)$ are employed.

To facilitate comparison of energetics with previous studies, additional DFT-RPBE calculations are performed with both GPAW (a real-space PAW code) $[58,59]$ and Dacapo (a code using a planewave basis and Vanderbilt ultrasoft pseudo-potentials (USPP)).[53] For GPAW calculations, the density, effective potential, and wavefunctions are evaluated with a grid spacing of $0.18 \AA$. For Dacapo calculations, a cutoff energy of $340 \mathrm{eV}$ is used. The Pt lattice constants are determined by fitting to an equation of state, [60] and the resulting values are 4.01 and $4.02 \AA$ with GPAW and Dacapo, respectively.

$\mathrm{Pt}$ (111) surfaces are modeled by repeated Pt slabs with at least $14 \AA$ of vacuum perpendicular to the slab surfaces. The oxygenated species are adsorbed on the top side of the slab, and dipole corrections are employed to screen the artificial interaction through the vacuum region. For slabs with thickness $\mathrm{L}$, the topmost $n$ layers $(n<=\mathrm{L} / 2)$, as well as the adsorbates, are allowed to relax, and the remaining layers are fixed in their bulk configuration. $\mathrm{Pt}(111)$ surfaces are modeled with supercells $(\sqrt{3} \times \sqrt{3}),(2 \times 2), \mathrm{c}(6 \times 2), \mathrm{c}(6 \times 4),(3 \times 3),(\sqrt{37} \times$ $\sqrt{37})$, and $(\sqrt{39} \times \sqrt{39})$, where $(9 \times 9 \times 1),(7 \times 7 \times 1),(4 \times 7 \times 1),(4 \times 4 \times 1),(5 \times 5 \times 1),(2 \times 2 \times 1)$ and $(2 \times 2 \times 1)$ k-point grids are used, respectively.

To evaluate the effect of slab thickness on the energetics, tests of the effect on surface energies, adsorption energies, reaction energies, and geometries, with slabs of up to $12 \mathrm{ML}$, are performed. The energies show clear oscillations with respect to the thickness of the slab.[61-63] As an example, the $\mathrm{O}^{*}$ (where “*” indicates adsorption on the surface) binding energy and the formation energy of $\left(\mathrm{H}_{2} \mathrm{O}-\mathrm{OH}\right) / \mathrm{Pt}(111)-(\sqrt{3} \times \sqrt{3})$ overlayers from $\mathrm{H}_{2} \mathrm{O}$ vapor and adsorbed $\mathrm{O}$ * are plotted in Figure 2 as a function of the slab thickness (see the Supporting Information for additional slab thickness tests). Clearly, the energetics strongly depend on the thickness and on the functional, and in order to achieve convergence of the reaction energies, slab thicknesses of eight layers are required. In what follows, the thermodynamic data for adsorbed $\mathrm{O}^{*}, \mathrm{OH}^{*}$, and most water bilayers correspond to this thickness. However, for water bilayers with unit cells of $\operatorname{Pt}(111)-(\sqrt{37} \times \sqrt{37})$ and $\operatorname{Pt}(111)-(\sqrt{39} \times \sqrt{39})$, the calculations are performed employing six layer slabs. Test calculations demonstrate that weak $\mathrm{H}_{2} \mathrm{O}-\mathrm{Pt}$ bonds are not as sensitive to the thickness of the slab as are the other strongly adsorbed species, and six and eight layer slabs give adsorption energy differences less than $1 \mathrm{meV} / \mathrm{H}_{2} \mathrm{O}$ (see Supporting Information). We note that convergence of slab thickness also depends on the properties studied. For AIMD simulations, as we are mainly interested in the structures of local energy minima, which are less sensitive to the thickness than are the energetics themselves (see Supporting Information), calculations are also carried out using six layer slabs. However, for 
some other properties, such as surface energy (see Supporting information) and surface stress, [64] thicker slabs may be required.

All AIMD simulations are performed in the canonical ensemble at a temperature of 400 $\mathrm{K}$ with a time step of $1 \mathrm{fs}$ and a total simulation time $10 \mathrm{ps}$. The simulations are initiated with a local geometry optimization and deuteration, and the systems are quenched to $0 \mathrm{~K}$ after every 2 ps of simulation time, followed by subsequent conversion back to hydrogen and geometry optimization to identify local minima.

The 01s core-level binding energy $\varepsilon$ (- $\varepsilon$ is the eigenvalue) is calculated with the final state approximation following a procedure described in references $[42,65]$ :

$\varepsilon=E\left(\mathrm{n}_{\mathrm{c}}-1\right)-\mathrm{E}\left(\mathrm{n}_{\mathrm{c}}\right)$

where $E\left(n_{c}\right)$ is the ground state total energy, and $E\left(n_{c}-1\right)$ is the static total energy from a constrained ground state calculation with an $\mathrm{O} 1 \mathrm{~s}$ electron core hole.

\section{Results}

We begin by benchmarking the Density Functional Theory energetics against experimental data, including the bulk water sublimation energy, [66] the water bilayer formation energy, the $\mathrm{O}^{*}$ adsorption energy, and the $\left(\mathrm{H}_{2} \mathrm{O}-\mathrm{OH}\right)$ overlayer formation energy from reaction of water vapor with adsorbed $\mathrm{O}^{*}$ measured with highly accurate calorimetry by Campbell and coworkers (Table 1).[11, 21, 22] The surface calorimetric data are very important to the present analysis, and indeed, it would be impossible to complete the benchmarking exercise without them.

We find that the calculated energetics are sensitive to the functionals used, as is true for adsorption energies and formation energies reported in previous work.[53-55, 67-70] For bulk water and the water bilayer on Pt(111), optPBE and RPBE overestimate and underestimate the binding energies with magnitudes equal to or greater than $100 \mathrm{meV} / \mathrm{H}_{2} \mathrm{O}$. BEEF slightly underestimates the binding energies (0.03-0.05 eV) and has the best overall performance on both bulk ice and the water bilayer. For the water bilayer alone, the binding energy with PBE is essentially identical to the experimental results, as the absence of the weak non-local Van der Waals interaction is compensated by the slightly overestimated hydrogen bond strength.[11, 69]

For oxygen adsorption with respect to gas phase $\mathrm{H}_{2} \mathrm{O}$ and $\mathrm{H}_{2}$ reference states,

$\mathrm{H}_{2} \mathrm{O}(\mathrm{g})+* \rightarrow \mathrm{O}^{*}+\mathrm{H}_{2}(\mathrm{~g})$

the adsorption energies are $1.33 \mathrm{eV}, 1.38 \mathrm{eV}, 1.04 \mathrm{eV}, 1.21 \mathrm{eV}, 1.41 \mathrm{eV}$ and $1.58 \mathrm{eV}$ with $\mathrm{PBE}$, RPBE, optPBE, BEEF, GPAW-RPBE and Dacapo-RPBE, respectively, which are $0.32 \mathrm{eV}, 0.27 \mathrm{eV}$, $0.61 \mathrm{eV}, 0.44 \mathrm{eV}, 0.24$, and $0.07 \mathrm{eV}$ more exothermic than the experimental value of $1.65 \mathrm{eV}$. For the formation energy of the mixed $\left(\mathrm{H}_{2} \mathrm{O}-\mathrm{OH}\right)$ overlayer from water vapor and adsorbed oxygen, 
PBE has the best performance, with a reaction energy of $-1.92 \mathrm{eV}$, which is only $0.05 \mathrm{eV}$ different from the experimental result of $-1.97 \mathrm{eV}$. The reaction energies with other functionals, including RPBE, optPBE, BEEF, RPBE(GPAW) and RPBE(Dacapo), are -1.02eV, -2.42eV, -1.75 eV, -0.92, - 1.06 $\mathrm{eV}$, with corresponding errors compared to experiment of $0.95 \mathrm{eV},-0.45,0.22 \mathrm{eV}, 1.05$ and 0.91 $\mathrm{eV}$, respectively. We note that the negligible error with PBE can be understood based on the following two arguments. First, even though the absolute errors in $\mathrm{O}^{*}$ and $\mathrm{OH}^{*}$ adsorption energies are unknown, since the reactant $\left(1 \mathrm{O}^{*}\right)$ and the products $\left(2 \mathrm{OH}^{*}\right)$ have the same total bond order, the errors are approximately aligned and are nearly cancelled out in the reaction energy. Therefore, the residual errors in the adsorbed $\left(\mathrm{H}_{2} \mathrm{O}-\mathrm{OH}\right)$ overlayer are mainly associated with the $\mathrm{H}_{2} \mathrm{O}-\mathrm{Pt}$ interaction and with intermolecular hydrogen bonds, which are balanced in $\mathrm{PBE}$, as evidenced by its satisfactory treatment of the $\mathrm{H}_{2} \mathrm{O}$ bilayer, as discussed above. These two arguments are further supported by results with the other functionals. Indeed, as is shown in Supporting Information, the errors in the reaction energy are directly proportional to the corresponding errors on the water bilayer formation energies.

Based on the above two arguments, and assuming that $\mathrm{H}_{2} \mathrm{O}$ in the mixed $\left(\mathrm{H}_{2} \mathrm{O}-\mathrm{OH}\right)$ overlayer has the same chemical potential as that in the water bilayer,[8-10] reaction [3] can be modified by subtracting twice the $\mathrm{H}_{2} \mathrm{O}$ bilayer formation energy (the latter is defined on a per water basis):

This reaction effectively provides a measure of the formation energy of hydrated hydroxyl groups in the well-defined water-OH overlayer, accounting explicitly for the stabilizing effect of hydrogen bonding on the adsorbed $\mathrm{OH}^{*}$ groups. Experimental data for reaction [4], along with calculated data from various density functionals, are given in Table 1. Because of the error cancellation of water molecules in the water bilayer and in the $\left(\mathrm{H}_{2} \mathrm{O}-\mathrm{OH}\right)$ overlayer, the errors of each functional in this reaction are much smaller than those in reaction [3], and PBE has the best agreement with an error of $0.06 \mathrm{eV}$ per reaction formula $(0.03 \mathrm{per} \mathrm{OH})$.

Given the promising performance described above, we use reaction [4] and the PBE functional to evaluate the relative stability of the other $\mathrm{OH}$ species with different hydration states (i.e. $\mathrm{H}_{2} \mathrm{O}(\mathrm{g})+\mathrm{O}^{*} \rightarrow 2 \mathrm{OH}^{*}$ (hydration state)), including partially hydrated $\mathrm{OH}$, adsorbed $\mathrm{OH}$ chains, and isolated/non-hydrated $\mathrm{OH}$ groups. The stability of isolated $\mathrm{OH}$ and the $\mathrm{OH}$ chains are evaluated with a $1 \mathrm{OH} / \mathrm{Pt111}-(2 \times 2)$ cell and a $20 \mathrm{H} / \mathrm{Pt}(111)-(\sqrt{3} \times \sqrt{3})$ cell, respectively (Figure 3). In the latter case, each $\mathrm{OH}$ accepts/donates one hydrogen bond from/to neighboring $\mathrm{OH}$ species. The stability of the partially hydrated $\mathrm{OH}$ species, in turn, is evaluated using a $(3 \times 3)$ unit cell with two water molecules, two fully hydrated $\mathrm{OH}$ molecules (each forms three hydrogen bonds with neighbor $\mathrm{H}_{2} \mathrm{O}$ or $\mathrm{OH}$ ), one partially hydrated $\mathrm{OH}$ molecule (it accepts a single hydrogen bond from a neighboring $\mathrm{H}_{2} \mathrm{O}$ molecule), and one $\mathrm{OH}$ within a chain-like structure, by assuming that $\mathrm{H}_{2} \mathrm{O}$ in the mixed $\left(2 \mathrm{H}_{2} \mathrm{O}-4 \mathrm{OH}\right)$ overlayer has the same chemical potential as that in the water bilayer and that the fully hydrated $\mathrm{OH}$ and the chain $\mathrm{OH}$ have the same intrinsic stability that they have in their pure forms; in this case, reaction [4] could be written as $2 \mathrm{H}_{2} \mathrm{O}(\mathrm{g})+2 \mathrm{O}^{*} \rightarrow 2 \mathrm{OH}^{*}$ (hydrated) $+\mathrm{OH}^{*}$ (partially hydrated) $+\mathrm{OH}^{*}$ (chain). We note that the $\left(2 \mathrm{H}_{2} \mathrm{O}-4 \mathrm{OH}\right) / \mathrm{Pt}(111)-(3 \times 3)$ configuration is generated by removing one hydrogen atom from a $3\left(\mathrm{H}_{2} \mathrm{O}-\mathrm{OH}\right) / \mathrm{Pt}(111)-(3 \times 3)$ super structure (Figure 3$)$. The relative stabilities of the four types of 
$\mathrm{OH}$ species, as determined by reaction [4], are given in Table 2. It is clear that it is endothermic to form $\mathrm{OH}$ chains and isolated $\mathrm{OH}$ species by reaction of $\mathrm{O}^{*}$ with water vapor. Further, considering that formation of water bilayers or multilayer ice is exothermic by approximately $0.6 \mathrm{eV} / \mathrm{H}_{2} \mathrm{O}$, only fully hydrated $\mathrm{OH}$ is likely to be stable compared to water gas and $\mathrm{O}^{*}$ at low temperatures.

To extend our analysis of the stability of adsorbed $\mathrm{OH}$ species to electrochemicallyrelevant conditions, we refer the energetics of various adsorbed $\mathrm{OH}$ species to an $\mathrm{H}_{2} \mathrm{O}(\mathrm{g})$ and $\mathrm{H}_{2}(\mathrm{~g})$ reference state $[9,70,71]$ corresponding to the reaction

$\mathrm{H}_{2} \mathrm{O}(\mathrm{g})+* \rightarrow \mathrm{OH}^{*}+0.5 \mathrm{H}_{2}(\mathrm{~g})$

We note that switching reference states for the adsorbed $\mathrm{OH}^{*}$ energies, as we do in equation [5], results in a change of energetics on an absolute scale, but it does not influence the relative stability of each $\mathrm{OH}^{*}$ species. The results are given in Table 1 and Table 3. The energetics determined according to the reference states described in reactions [2] and [5] are combined with simple zero point energy, heat capacity and entropy corrections to establish free energies for the transformation of stoichiometrically appropriate amounts of molecular oxygen and hydrogen to adsorbed $\mathrm{O}^{*}, \mathrm{OH}^{*}$, and liquid water; the free energy of $\mathrm{O}_{2}(\mathrm{~g})$, in turn, is corrected to ensure that the formation free energy of $\mathrm{H}_{2} \mathrm{O}(\mathrm{l})$ from molecular $\mathrm{H}_{2}(\mathrm{~g})$ and $1 / 2 \mathrm{O}_{2}(\mathrm{~g})$ matches experiment (see Supporting Information). Finally, the proton and the electrode electrochemical potentials are introduced through use of the computational hydrogen electrode concept, where

$$
0.5 \mathrm{H}_{2} \rightarrow \mathrm{H}^{+}+\mathrm{e}^{-}
$$

is in equilibrium at OV versus standard hydrogen electrode under standard condition (298.15 K, 1 bar and $\mathrm{pH}=0)$, as described in several references.[9, 70, 72]

At $\mathrm{U}=0.8 \mathrm{~V}$, the experimental data, which have been adopted from the detailed calorimetric measurements described above and adjusted using the same free energy corrections discussed in the preceding paragraph (Table 1), show that all reaction steps are exothermic in energy (Figure 4). However, the electrochemical (electron/proton transfer) steps are actually predicted to be endothermic with the data from all density functionals, and the maximum free energy barriers are $0.14 \mathrm{eV}, 0.30 \mathrm{eV}, 0.42 \mathrm{eV}, 0.23 \mathrm{eV}, 0.31 \mathrm{eV}$ and $0.15 \mathrm{eV}$ with PBE, RPBE, optPBE and BEEF, GPAW-RPBE and Dacapo-RPBE, respectively (the onset potentials with the these functionals, vs. SHE, are $0.69 \mathrm{~V}, 0.50 \mathrm{~V}, 0.39 \mathrm{~V}, 0.59 \mathrm{~V}, 0.49 \mathrm{~V}$ and $0.65 \mathrm{~V}$, respectively). The results for PBE (PAW core treatment) and Dacapo-RPBE (ultrasoft pseudopotential core treatment) are close to the experimental results, and these functionals and core potential treatments should provide relatively reliable descriptions of ORR electrochemistry on Pt(111). We emphasize, in passing, that it is important to consider both the density functional and core potential treatment when making comparisons of DFT codes and methods. Additionally, we note that, although the results with the other functionals correspond less closely to the experiments, it is still expected that predictions of trends across different transition metals or different platinum alloys will be reliable.

The relatively small errors with the PBE calculations suggest that analyses on $\mathrm{Pt}(111)$ with this functional can serve as good references to study the relative stability of $\mathrm{O}^{*}$ and $\mathrm{OH}^{*}$ in different hydration environments, or even on different surfaces, for ORR applications. Indeed, a 
simple approach would be to correct the PBE errors in $\mathrm{O}^{*}$ and $\mathrm{OH}^{*}$ energies to the experimental values and to further assume that these corrections are constant for the adsorption of corresponding species in different hydration environments or on entirely different surfaces. As a simple example, we have used this strategy to evaluate the relative energetics of the metastable $\mathrm{OH}$ species (Figure 4b). Clearly, non-hydrated $\mathrm{OH}, \mathrm{OH}$ chains, and partially hydrated $\mathrm{OH}$ (Figure 3) all are predicted to be unstable intermediates under ORR conditions, though the former (non-hydrated $\mathrm{OH}$ ) was proposed to be an abundant intermediate on Pt nanoparticles with diameters of 10-20nm for which close-packed terraces are the most abundant surface 276 facets.[7]

\section{XPS simulations}

To further evaluate the stability of different forms of $\mathrm{OH}$ on $\mathrm{Pt}(111)$ surfaces, we turn to a comparison of experimental and simulated X-ray photoelectron spectroscopy (XPS) signatures. XPS has been widely used to identify oxygenated species at water/Pt interfaces under both vacuum and in-situ electrocatalytic conditions. Numerous peaks (core-level binding energies) and core-level shifts (CLSs) have been observed and correlated with particular structures, including atomic $\mathrm{O}^{*}$ adsorbed on the Pt(111) surface with an O1s binding energy of $529.9 \mathrm{eV},[7$, 23] an adsorbed water bilayer on Pt(111) with an O1s binding energy $532.2 \mathrm{eV}$ (CLS of $2.3 \mathrm{eV}$ compared to the $01 \mathrm{~s}$ binding energy of $\left.\mathrm{O}^{*}\right),[23,25]$ a mixed $\left(\mathrm{H}_{2} \mathrm{O}+\mathrm{OH}\right)$ overlayer on $\mathrm{Pt}(111)$ with an $01 \mathrm{~s}$ binding energy of $531.6 \mathrm{eV}$ from the water molecules (1.7 eV CLS compared to the O1s binding energy of $\mathrm{O}^{*}$ ), an $\mathrm{O} 1 \mathrm{~s}$ binding energy of $530.1 \mathrm{eV}$ from fully hydrated $\mathrm{OH}(0.2 \mathrm{eV}$ CLS compared to the $\mathrm{O} 1 \mathrm{~s}$ binding energy of $\left.\mathrm{O}^{*}\right),[23]$ and a non-hydrated $\mathrm{OH}$ on close-packed terrace sites of large Pt nanoparticles with a binding energy of $531 \mathrm{eV}$ (CLS of $1.1 \mathrm{eV}$ compared to the O1s binding energy of $0^{*}$ ).[7] First principles-based XPS simulations could serve as an effective tool to both verify these experimental assignments and also to further test the reliability of the thermodynamic and energetic arguments presented in the previous sections. We have therefore carried out such simulations based on the structures depicted in Figure 1 and Figure 3.

Instead of absolute core-level binding energies $(\varepsilon)$, the computational analysis is focused primarily on core-level shifts, which can be efficiently predicted by DFT. O* is employed as a reference state for the CLS energies (CLS $=\varepsilon-\varepsilon\left(O^{*}\right)$ where $\varepsilon$ is the $O 1$ s core-level binding energy calculated using equation[1]), as this feature has been extensively described in the literature with an absolute 01s binding energy of $529.9 \mathrm{eV}$. The calculated CLS's are broadened by a Gaussian function with a full width of half maximum (FWHM) of $1 \mathrm{eV}$, which is a typical value in experiments.[23] To evaluate the performance of the various DFT functionals for the calculation of the relative CLS's, we employ a water bilayer model corresponding to $4 \mathrm{H}_{2} \mathrm{O}$ molecules per c(6x4) Pt(111) unit cell. The calculated CLS's are $2.5 \mathrm{eV}, 2.6 \mathrm{eV}, 2.6 \mathrm{eV}$ and $2.7 \mathrm{eV}$ for PBE, RPBE, optPBE and BEEF, respectively (see also Supporting Information). The small differences imply that the CLS results are not too sensitive to the choice of functional. For this reason, and given its satisfactory prediction of the thermodynamics of the surface species studied in this work, we use the PBE functional in the remainder of the simulations.

For the most stable water bilayer, $29 \mathrm{H}_{2} \mathrm{O} / \mathrm{Pt}(111)-(\sqrt{39} \times \sqrt{39})$ (Figure 1a), the predicted $\mathrm{O} 1 \mathrm{~S} \mathrm{CLS}^{\prime} \mathrm{s}$, again referred to the core level binding energy of $\mathrm{O}^{*}$, are around $2.2 \mathrm{eV}$ (Figure 5), which is slightly smaller than the experimental value of $2.3 \mathrm{eV} .[23,25]$ For the mixed $\left(\mathrm{H}_{2} \mathrm{O}-\mathrm{OH}\right.$ ) overlayer (Figure 1c), the predicted $\mathrm{O} 1 \mathrm{~s} \mathrm{CLS}^{\prime}$ s of $\mathrm{H}_{2} \mathrm{O}$ and $\mathrm{OH}$ are $2.0 \mathrm{eV}$ and $0.4 \mathrm{eV}$, 
respectively, which are slightly larger than the broad peaks at $1.7 \mathrm{eV}$ and $0.2 \mathrm{eV}$ in experiments.[23] For non-hydrated $\mathrm{OH}$ (Figure 3c), however, the predicted $\mathrm{O} 1 \mathrm{~s}$ CLS is $-0.7 \mathrm{eV}$ (Figure 6), which is $1.8 \mathrm{eV}$ smaller than the experimentally assigned value of $1.1 \mathrm{eV}$. [7] For completeness, we additionally evaluate the $\mathrm{O} 1 \mathrm{~s} \mathrm{CLS}^{\prime} \mathrm{s}$ of $\mathrm{OH}$ chains and partially hydrated $\mathrm{OH}$ (Figure 3c), which are $-1.0 \mathrm{eV}$ and $-0.1 \mathrm{eV}$ (Figure 6), respectively. The predicted data on the water bilayer and the mixed $\left(\mathrm{H}_{2} \mathrm{O}-\mathrm{OH}\right)$ overlayer show only small quantitative differences compared to the experimental results. This favorable comparison not only confirms the experimental assignments, but also demonstrates the reliability of the XPS simulations. On the other hand, there are significant differences between experiment and theory for the nonhydrated $\mathrm{OH}$ species. The large discrepancies, in turn, suggest some uncertainties about the assignment of the feature at $1.1 \mathrm{eV}$ to non-hydrated $\mathrm{OH}$, and the absence of a peak near $-0.7 \mathrm{eV}$ in the experiments also implies that non-hydrated $\mathrm{OH}$ is most likely not present at ORR-relevant potentials although we cannot exclude the possibility that it may exist at somewhat higher voltages.[73] These results are fully consistent with the thermodynamic arguments presented in the above session, which demonstrate that non-hydrated $\mathrm{OH}$ is not energetically favorable on $\mathrm{Pt}(111)$.

As the XPS experiments that identified non-hydrated $\mathrm{OH}$ were conducted under conditions approximating those of the ORR in electrochemical environments, it is possible that the measured feature at $1.1 \mathrm{eV}$ (vs. the $\mathrm{O}^{*} \mathrm{CLS}$ ) could be related to the presence of either molecular $\mathrm{O}_{2}$ or additional water bilayers in the experiments. To evaluate these possibilities, we simulate the explicit adsorption of $\mathrm{O}_{2}$, and we also consider the coexistence of multilayer water above the stable $\left(\mathrm{H}_{2} \mathrm{O}-\mathrm{OH}\right)$ overlayer. For $\mathrm{O}_{2}$ adsorption (Figure 6 and Figure 7), the calculated CLS of $0.95 \mathrm{eV}$ is very close to the values reported in experiments. As $\mathrm{O}_{2}{ }^{*}$ is not a strongly adsorbed intermediate,[9] however, it may contribute the experimental observed peak to some extent, but the signature may not be sufficiently strong to fully explain the experimental observation. For the effect of additional water bilayers, we have introduced water molecules in the supercell of $4\left(\mathrm{H}_{2} \mathrm{O}-\mathrm{OH}\right) / \mathrm{Pt}(111)-\mathrm{c}(6 \times 4)$, which effectively fill the vacuum region between the slab model and the corresponding periodic images, and we conduct AIMD simulations to obtain the most stable structures (see the Computational details section for more information). The AIMD simulations indicate that $\mathrm{H}_{2} \mathrm{O}-\mathrm{OH}$ complex at the water/Pt(111) interface largely preserves the configuration of the isolated $\left(\mathrm{H}_{2} \mathrm{O}-\mathrm{OH}\right)$ overlayer. However, the presence of extra water molecules does lift the constraint of 'perfect' hydrogen bond networks in the $\left(\mathrm{H}_{2} \mathrm{O}-\mathrm{OH}\right)$ overlayer by randomly breaking in-network hydrogen bonds and forming additional hydrogen bonds with water in the second layer. These rearrangements (Figure 7) significantly shorten and consequently strengthen the remaining in-network hydrogen bonds, especially those from $\mathrm{H}_{2} \mathrm{O}$ to $\mathrm{OH}$ (shortened from $\sim 1.75 \AA$ to $~ 1.55 \AA$, on average). Accordingly, the O1s binding energies from both $\mathrm{H}_{2} \mathrm{O}$ and $\mathrm{OH}$ in contact with $\mathrm{Pt}$, in comparison with that from the isolated $\left(\mathrm{H}_{2} \mathrm{O}-\mathrm{OH}\right)$ overlayer, shift to lower energies, resulting in an average CLS of $1.2 \mathrm{eV}$ for $\mathrm{H}_{2} \mathrm{O}(0.2 \mathrm{eV}$ for $\mathrm{OH})$. As the mixed $\mathrm{H}_{2} \mathrm{O}-\mathrm{OH}$ layer is energetically stable at the water/Pt(111) interface under ORR conditions, the $\mathrm{H}_{2} \mathrm{O}$ that this layer contains may contribute to the experimentally observed CLS $1.1 \mathrm{eV}$. Similar trends in the hydrogen bond length and O1s CLSs are also observed in $\mathrm{OH}$-rich $\left(\mathrm{H}_{2} \mathrm{O}-\mathrm{OH}\right.$ ) layers (Figure 3 and Figure 6) and in $\mathrm{H}_{2} \mathrm{O}-\mathrm{OH}$ dimers (see Supporting Information). However, we note that we cannot completely exclude other possible origins of the signature at 
$1.1 \mathrm{eV}$. For example, similar CLS's have been reported for Pt (hydroxy)oxide, which, however, is generally produced at much higher potentials.[73]

For the $\left(\mathrm{H}_{2} \mathrm{O}+\mathrm{OH}\right)$ complex at the water/Pt(111) interface, the spontaneous

\section{Conclusions}

We have compared first principles-based energetic and XPS simulations with state-of-the-art experimental data to distinguish the oxygenated species at the water/Pt(111) interface under UHV and ORR conditions. To overcome the limitations of DFT in the prediction of absolute adsorbate stability, we have first established a reference scheme to reliably evaluate the stability of various oxygenated species by comparing calculations using well defined water bilayers, mixed $\mathrm{H}_{2} \mathrm{O}-\mathrm{OH}$ overlayers and chemisorbed oxygen with high quality experimental calorimetric measurements. Simulations of XPS spectra for a variety of oxygenated structures at the water/Pt interface show that various oxygenated species do have rich and unique $01 \mathrm{~s}$ binding energy fingerprints, and the first principles-based XPS simulations can reliably predict the relative core-level shifts. The broadness and the possible overlap of core-level binding energies from species in distinct local environments, on the other hand, demonstrates the important guiding role of first principles-based XPS simulations on the assignment of new XPS peaks.

Both energetics and XPS simulations suggest that, instead of non-hydrated $\mathrm{OH}$, hydrated $\mathrm{OH}$ is likely the abundant species under ORR conditions. The O1s core level binding, which was assigned to the non-hydrated $\mathrm{OH}$ in a recent ambient pressure XPS study, may actually originate from water molecules in an $\left(\mathrm{H}_{2} \mathrm{O}-\mathrm{OH}\right)$ complex at the water/Pt interface. The flexibility of hydrogen bonding rearrangements at the water/Pt interface makes it facile to form extended $\mathrm{H}_{2} \mathrm{O}-\mathrm{OH}$ networks, not only on $\mathrm{Pt}(111)$, but also on various defect sites and on other catalysts. The ubiquity of these interactions, in turn, suggests that manipulating covalent $\mathrm{OH} / \mathrm{metal}$ bonds remains the key principle for the design of improved ORR catalysts. 


\section{Acknowledgements}

398 This work was supported through a DOE Early Career Award of the Chemical Sciences, 399 Geosciences and Biosciences Division, Office of Basic Energy Sciences, Office of Science, U.S. 400 Department of Energy. Use of the Center for Nanoscale Materials was supported by the U.S. 401 Department of Energy, Office of Science, Office of Basic Energy Sciences, under Contract E402 AC02-06CH11357. We gratefully acknowledge the computing resources provided on Blues and 403 Fusion, a high-performance computing cluster operated by the Laboratory Computing Resource 404 Center at Argonne National Laboratory. Use of computational resources through the National 405 Energy Research Scientific Computing Center (NERSC) is also gratefully acknowledged. 

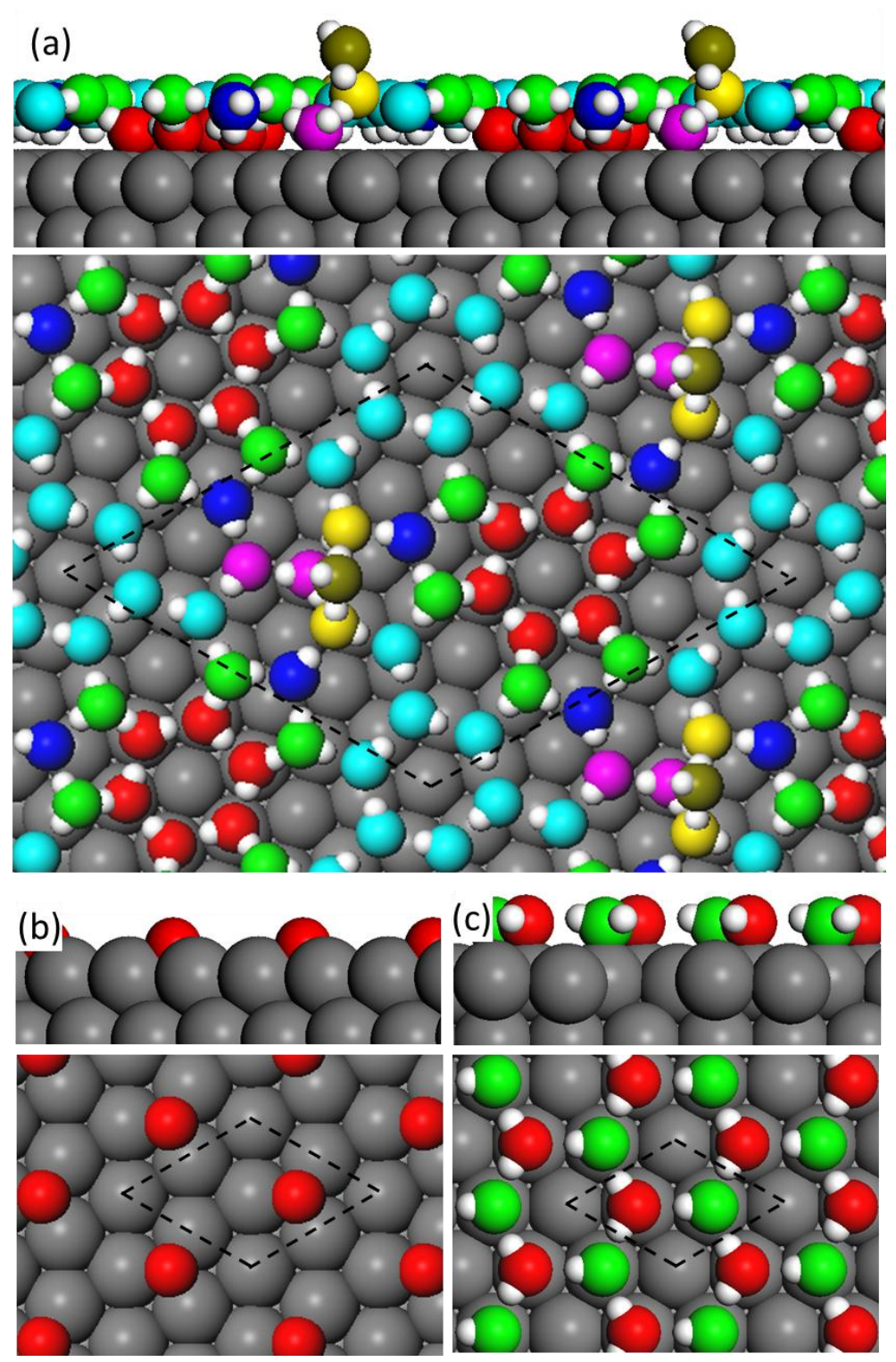

408 Figure 1. Side and top views of (a) $29 \mathrm{H}_{2} \mathrm{O} / \mathrm{Pt}(111)-(\sqrt{39} \times \sqrt{39})$, (b) $\mathrm{O} / \mathrm{Pt}(111)-(2 \times 2)$, and (c) $409\left(\mathrm{H}_{2} \mathrm{O}-\mathrm{OH}\right) / \mathrm{Pt}(111)-(\sqrt{3} \times \sqrt{3})$ overlayer models. For the $29 \mathrm{H}_{2} \mathrm{O} / \mathrm{Pt}(111)-(\sqrt{39} \times \sqrt{39})$ structure, 410 we note that, in addition to water molecules in the bilayer, there is a water molecule (dark yellow) in the 411 2nd layer, as indicated. 

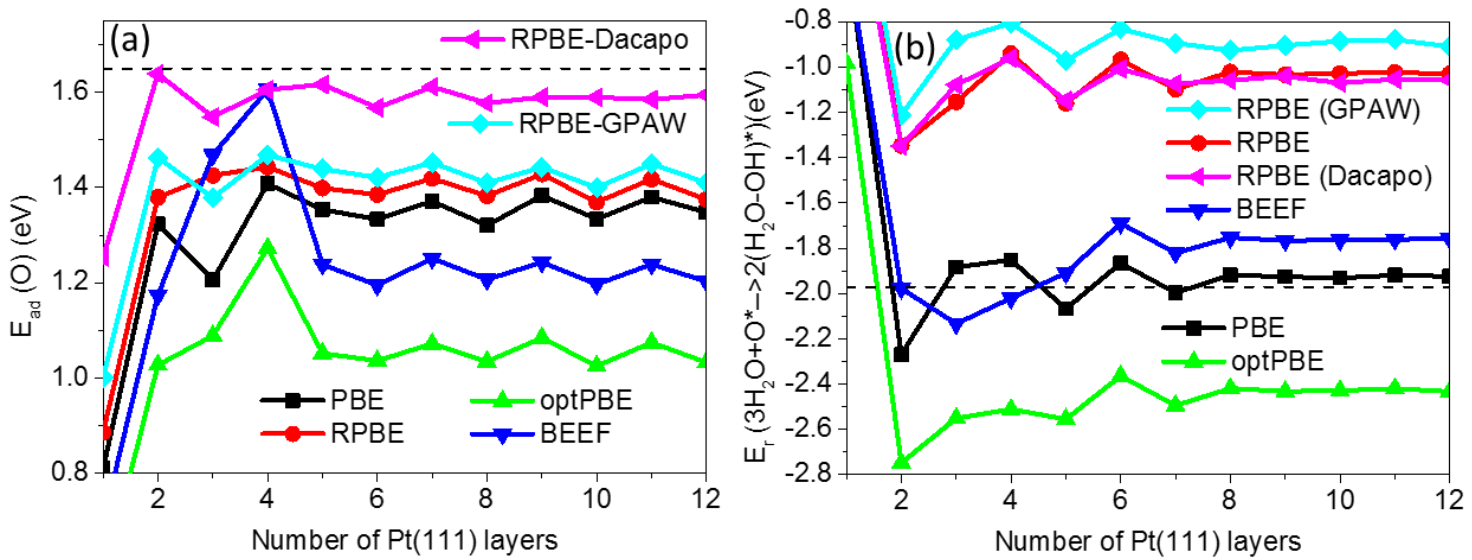

Figure 2. The calculated (a) $\mathrm{O}^{*}$ adsorption energy, referred to gas phase $\mathrm{H}_{2} \mathrm{O}$ and $\mathrm{H}_{2}$ reference states, and (b) formation energy of mixed $(\mathrm{H} 2 \mathrm{O}-\mathrm{OH})$ overlayers, referred to gas phase $\mathrm{H}_{2} \mathrm{O}$ and adsorbed $\mathrm{O}$ * reference states, as a function of platinum slab thickness. The experimental values are indicated by dashed lines (see Table 1). See Figure 1 for the models used in the calculations.
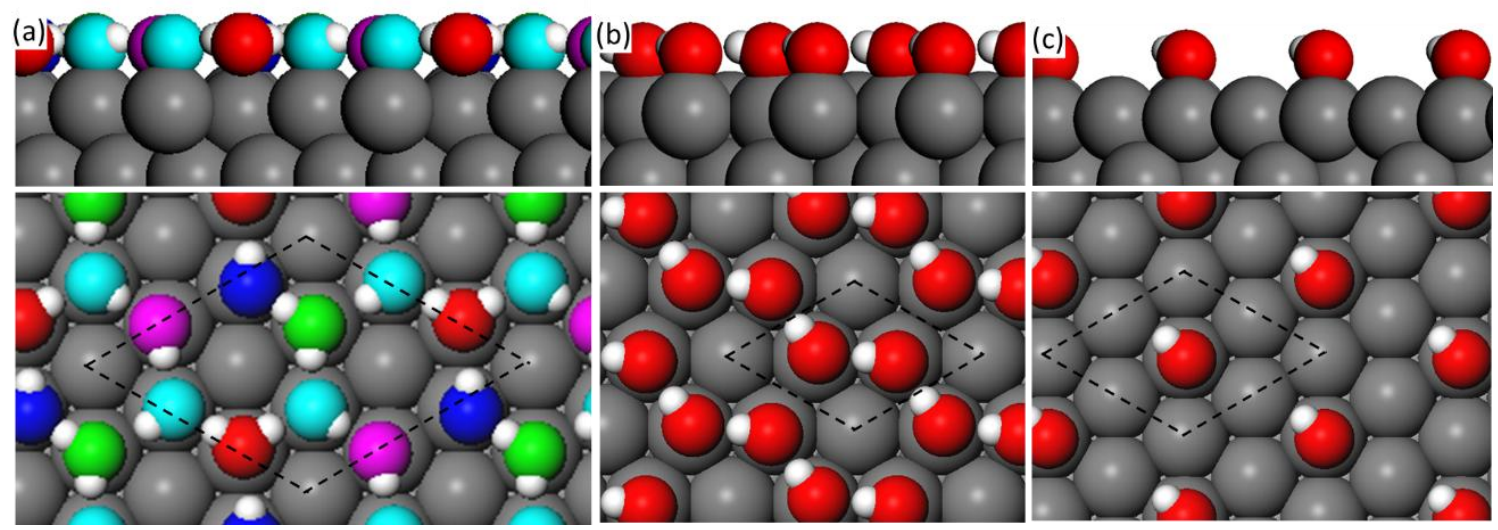

Figure 3. Side and top views of (a) $2\left(\mathrm{H}_{2} \mathrm{O}-2 \mathrm{OH}\right) / \mathrm{Pt}(111)-(3 \times 3)$, (b) $2 \mathrm{OH} / \mathrm{Pt}(111)-(\sqrt{3} \times \sqrt{3})$, (c)

$\mathrm{OH} / \mathrm{Pt}(111)-(2 \times 2)$ adsorption models, which are employed to evaluate the stability of partially hydrated $\mathrm{OH}$ (blue), $\mathrm{OH}$ chains, and isolate $\mathrm{OH}$ groups, respectively. 
(a)

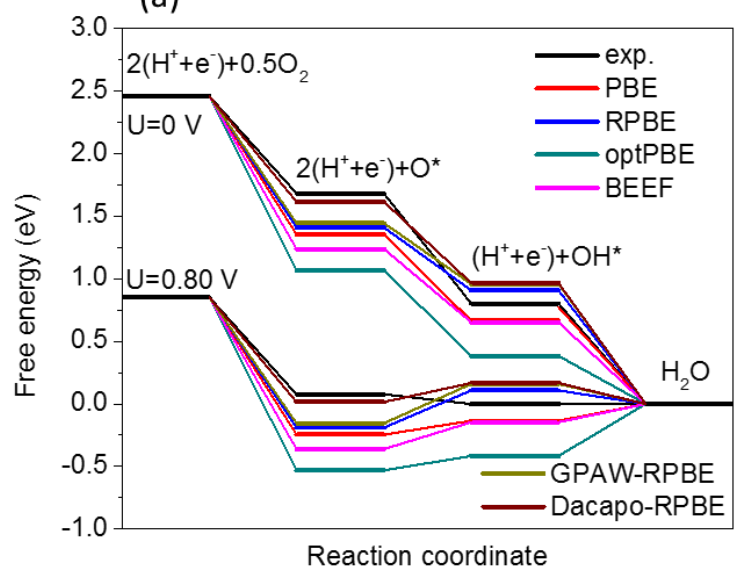

(b)

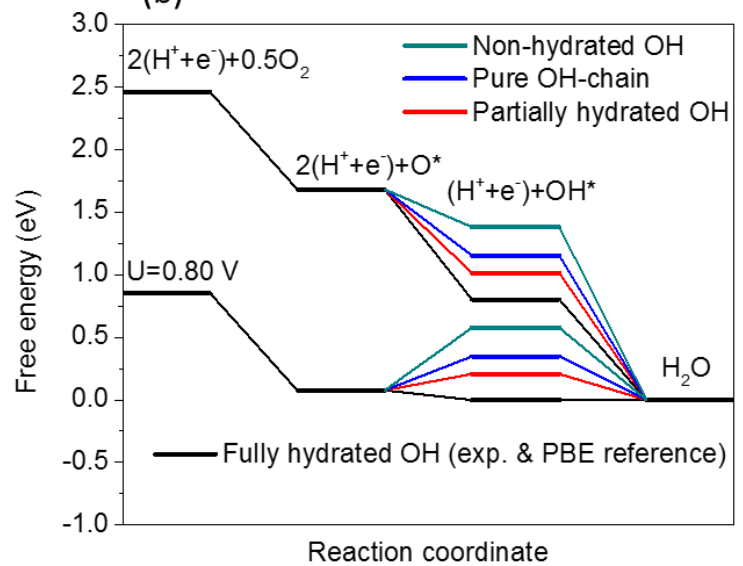

424

425

426

427

428

429

430

431

Figure 4. Free-energy diagram for oxygen reduction over $\mathrm{Pt}(111)$ surfaces (a) with different density functionals, and (b) for various $\mathrm{OH}$ species with a PBE-based reference scheme. For the latter, the absolute stability of various $\mathrm{OH}$ species is obtained by first calculating the relative stability with respect to the reference (here, hydrated $\mathrm{OH}$ on $\mathrm{Pt}(111)$ ) using PBE, and then referring to the experimental data of the reference (see the main text for details). The structures of each species are given in Figure 1 and Figure 3.
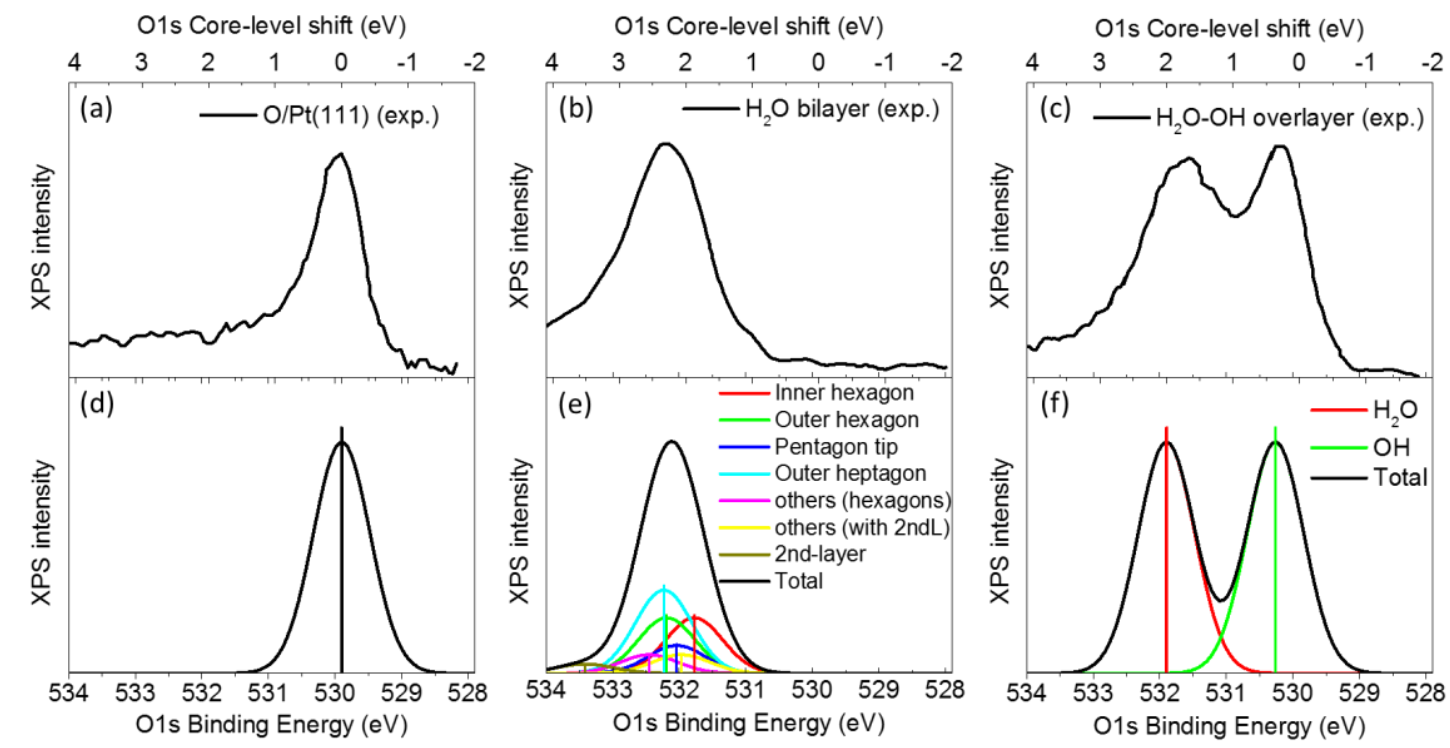

433

Figure 5. Experimental and simulated XPS spectra of $\mathrm{O}^{*}$, water bilayers, and $\left(\mathrm{H}_{2} \mathrm{O}-\mathrm{OH}\right)$ overlayers on $434 \mathrm{Pt}(111)$. See Figure 1 for the color scheme and the structure of each species. The experimental data, 435 which were measured under UHV conditions, are adopted from Ref.[23]. 


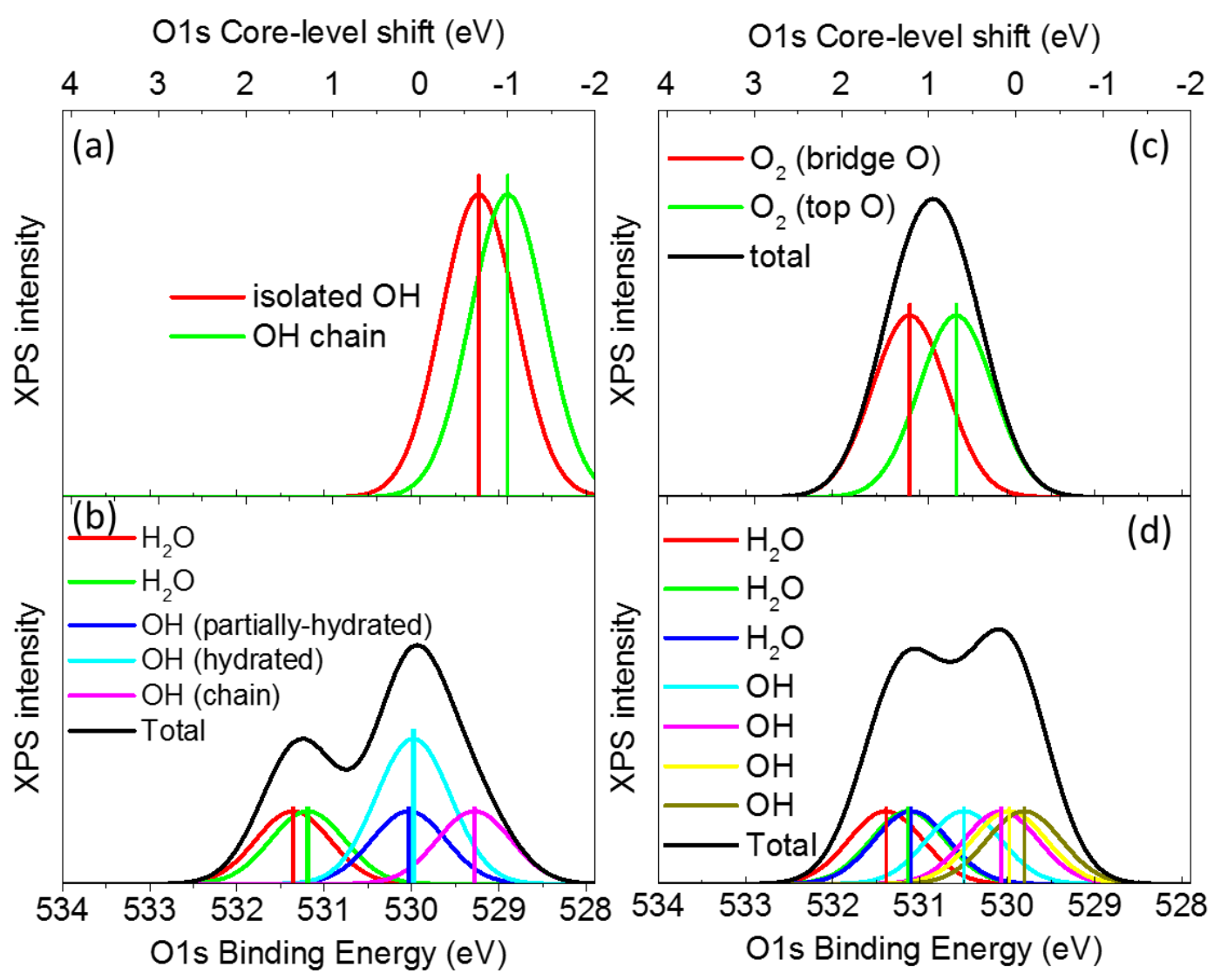

Figure 6. Simulated XPS spectra of (a) isolated $\mathrm{OH}$ and $\mathrm{OH}$ chains, (b) a $\mathrm{OH}$ rich $\left(\mathrm{H}_{2} \mathrm{O}-\mathrm{OH}\right)$ overlayer, $\left(2 \mathrm{H}_{2} \mathrm{O}-\right.$ $4 \mathrm{OH})$ on a $\mathrm{Pt}(111)$ surface, (c) $\mathrm{O}_{2}{ }^{*}$, and (d) a $\left(3 \mathrm{H}_{2} \mathrm{O}-4 \mathrm{OH}\right)$ complex at the water/Pt(111) interface. See 

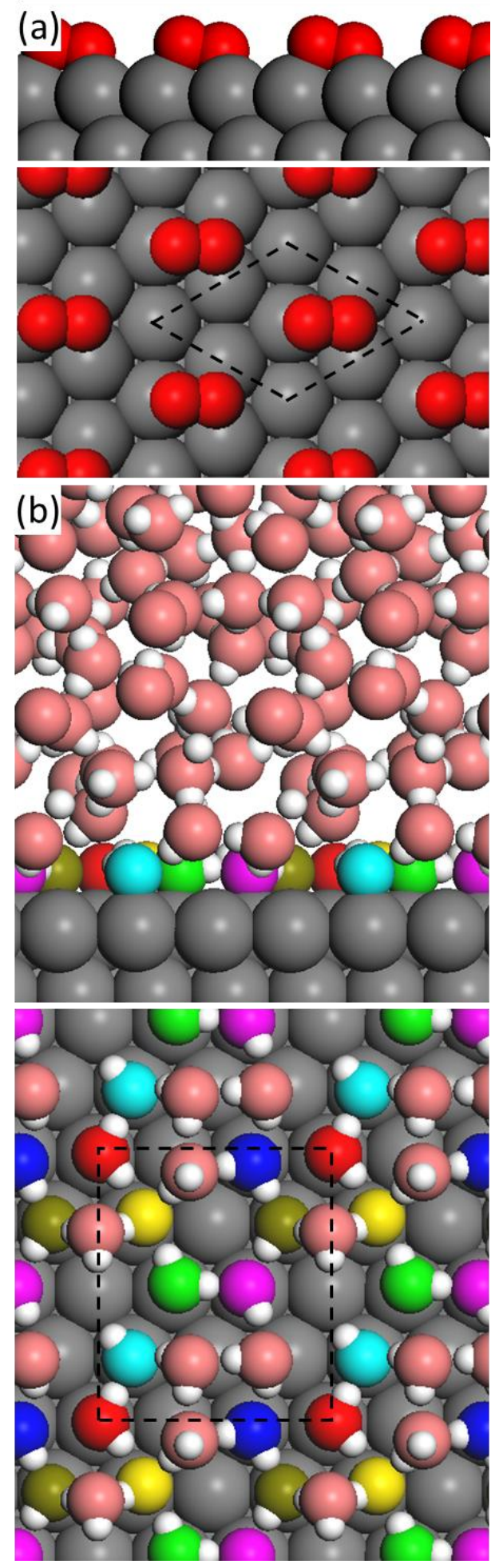

Figure 7. Side and top views of (a) $\mathrm{O}_{2}$ adsorption and (b) multilayer water adsorption on $\left(\mathrm{H}_{2} \mathrm{O}-\mathrm{OH}\right)$

overlayers on $\mathrm{Pt}(111)$. For the top view in (b), water molecules which are not in contact with surface $\left(\mathrm{H}_{2} \mathrm{O}-\right.$ $\mathrm{OH}$ ) complex have been removed from the figure to facilitate visualization. 

species on Pt(111)with experimental data. See Figure 1 for the models used in the calculations.

\begin{tabular}{|c|c|c|c|c|c|c|c|}
\hline dE & PBE & RPBE & optPBE & BEEF & $\begin{array}{c}\text { RPBE } \\
\text { (gpaw) }\end{array}$ & $\begin{array}{c}\text { RPBE } \\
\text { (dacapo) }\end{array}$ & $\operatorname{Exp}^{a}$ \\
\hline $\mathrm{H}_{2} \mathrm{O}(\mathrm{g}) \rightarrow \mathrm{Ice}-\mathrm{XI}$ & 8 & . & 1 & -0.58 & -0.47 & -0.46 & $-0.61^{b}$ \\
\hline $\mathrm{H}_{2} \mathrm{O}(\mathrm{g})+* \rightarrow \mathrm{H}_{2} \mathrm{O}$ (bilayer) & -0.60 & -0.38 & -0.73 & -0.55 & -0.36 & -0.37 & $-0.60^{c}$ \\
\hline $\mathrm{H}_{2} \mathrm{O}(\mathrm{g})+* \rightarrow \mathrm{O}^{*}+\mathrm{H}_{2}(\mathrm{~g})$ & 1.33 & 1.38 & 1.04 & 1.21 & 1.41 & 1.58 & $1.65^{d}$ \\
\hline $3 \mathrm{H}_{2} \mathrm{O}(\mathrm{g})+\mathrm{O}^{*} \rightarrow 2\left(\mathrm{H}_{2} \mathrm{O}-\mathrm{OH}\right)^{*}$ & -1.92 & -1.02 & -2.42 & -1.75 & -0.92 & -1.06 & $-1.97^{\mathrm{e}}$ \\
\hline $\mathrm{H}_{2} \mathrm{O}(\mathrm{g})+\mathrm{O}^{*} \rightarrow 2 \mathrm{OH}^{*}(\mathrm{hydr})$ & -0.71 & -0.28 & -0.98 & -0.22 & -0.22 & -0.36 & $-0.77^{f}$ \\
\hline $\mathrm{H}_{2} \mathrm{O}(\mathrm{g})+^{*} \rightarrow \mathrm{OH}^{*}(\mathrm{hydr})+0.5 \mathrm{H}_{2}(\mathrm{~g})$ & 0.31 & 0.55 & 0.03 & 0.29 & 0.60 & 0.60 & $0.44^{f}$ \\
\hline
\end{tabular}

a zero point energies have been removed to facilitate the comparison with the calculated data

448 'The adsorption energy is obtained by correcting a $\mathrm{k}_{\mathrm{B}} \mathrm{T}$ term on $\mathrm{H}_{2} \mathrm{O}(\mathrm{g})$ and the zero-point energies, based 449 on the measured adsorption heat at $120 \mathrm{~K}$ in Ref.[22].

$450 \quad{ }^{\mathrm{d}}$ Ref.[21]

451 ' The reaction energy is obtained by correcting a $\mathrm{k}_{\mathrm{B}} \mathrm{T}$ term on $\mathrm{H}_{2} \mathrm{O}(\mathrm{g})$ and zero-point energies, based on 452 the measured reaction heat at $150 \mathrm{~K}$ in Ref.[11]. chemical potential as that in water bilayer(see footnote $\mathrm{c}$ ) and by considering the $\mathrm{O}^{*}$ formation energy (see footnote d).

Table 2. The energy of formation of various $\mathrm{OH}$ species on $\mathrm{Pt}(111)$. See text and Figure 1 andFigure 3 for descriptions of the configurations.

\begin{tabular}{|c|c|c|c|c|}
\hline & $\mathbf{d E}$ & $\mathrm{dE}_{\mathrm{w} / \mathrm{ZPE}}$ & $d E, \exp$ & Method \\
\hline H2O+O*-->2OH*(hydrated) & -0.71 & -0.58 & -0.77 & PBE \\
\hline H2O+O*-->2OH*(partial-hydrated) & -0.30 & -0.16 & & PBE \\
\hline $\mathrm{H} 2 \mathrm{O}+\mathrm{O} *-->2 \mathrm{OH}^{*}$ (chain) & -0.04 & 0.12 & & PBE \\
\hline $\mathrm{H}_{2 \mathrm{O}+\mathrm{O}} *_{-->} \mathrm{2OH}^{*}($ non-hydrated) & 0.42 & 0.57 & & PBE \\
\hline
\end{tabular}

Table 3. The energetics of various $\mathrm{OH}$ species on $\mathrm{Pt}(111)$. See text and Figures 1 and 3 for descriptions of the configurations.

\begin{tabular}{|l|c|}
\hline $\mathrm{OH}^{*}$ & $\mathrm{dE}$ \\
\hline OH-hydrated & 0.31 \\
\hline OH-partial-hydrated & 0.52 \\
\hline OH chain & 0.66 \\
\hline OH-nonhydrated & 0.89 \\
\hline Exp (OH-hydrated) & 0.44 \\
\hline
\end{tabular}


[1] A.M. Gómez-Marín, R. Rizo, J.M. Feliu, Beilstein Journal of Nanotechnology, 4 (2013) 956-967.

[2] J. Greeley, N.M. Markovic, Energy Environ. Sci., 5 (2012) 9246-9256.

[3] M.J. Eslamibidgoli, J. Huang, T. Kadyk, A. Malek, M.H. Eikerling, Nano Energy.

[4] P. Strasser, S. Kühl, Nano Energy, doi:10.1016/j.nanoen.2016.1004.1047.

[5] H. Lv, D. Li, D. Strmcnik, A.P. Paulikas, N.M. Markovic, V.R. Stamenkovic, Nano Energy, doi:10.1016/j.nanoen.2016.1004.1008.

[6] F. Calle-Vallejo, J. Tymoczko, V. Colic, Q.H. Vu, M.D. Pohl, K. Morgenstern, D. Loffreda, P. Sautet, W. Schuhmann, A.S. Bandarenka, Science, 350 (2015) 185-189.

[7] H.S. Casalongue, S. Kaya, V. Viswanathan, D.J. Miller, D. Friebel, H.A. Hansen, J.K. Nørskov, A. Nilsson, H. Ogasawara, Nat Commun, 4 (2013) 2817.

[8] J. Greeley, I.E.L. Stephens, A.S. Bondarenko, T.P. Johansson, H.A. Hansen, T.F. Jaramillo, J. Rossmeisl, I. Chorkendorff, J.K. Nørskov, Nat. Chem., 1 (2009) 552-556.

[9] J.K. Nørskov, J. Rossmeisl, A. Logadottir, L. Lindqvist, J.R. Kitchin, T. Bligaard, H. Jonsson, J. Phys. Chem. B, 108 (2004) 17886-17892.

[10] V. Tripković, E. Skúlason, S. Siahrostami, J.K. Nørskov, J. Rossmeisl, Electrochim. Acta, 55 (2010) 7975-7981.

[11] W. Lew, M.C. Crowe, C.T. Campbell, J. Carrasco, A. Michaelides, J. Phys. Chem. C, 115 (2011) 23008-23012.

[12] J. Rossmeisl, G.S. Karlberg, T. Jaramillo, J.K. Norskov, Faraday Discuss., 140 (2009) 337-346.

[13] H.A. Hansen, V. Viswanathan, J.K. Nørskov, J. Phys. Chem. C, 118 (2014) 6706-6718.

[14] M. Busch, N.B. Halck, U.I. Kramm, S. Siahrostami, P. Krtil, J. Rossmeisl, Nano Energy, doi:10.1016/j.nanoen.2016.1004.1011.

[15] V. Viswanathan, H.A. Hansen, J. Rossmeisl, T.F. Jaramillo, H. Pitsch, J.K. Nørskov, J. Phys. Chem. C, 116 (2012) 4698-4704.

[16] M.E. Björketun, Z. Zeng, R. Ahmed, V. Tripkovic, K.S. Thygesen, J. Rossmeisl, Chem. Phys. Lett., 555 (2013) 145-148.

[17] Z. Zeng, M.H. Hansen, J.P. Greeley, J. Rossmeisl, M.E. Björketun, J. Phys. Chem. C, 118 (2014) 22663-22671.

[18] N.M. Marković, P.N. Ross Jr, Surf. Sci. Rep., 45 (2002) 117-229.

[19] F. Tian, R. Jinnouchi, A.B. Anderson, J. Phys. Chem. C, 113 (2009) 17484-17492.

[20] V. Fiorin, D. Borthwick, D.A. King, Surf. Sci., 603 (2009) 1360-1364.

[21] E.M. Karp, C.T. Campbell, F. Studt, F. Abild-Pedersen, J.K. Nørskov, J. Phys. Chem. C, 116 (2012) 25772-25776.

[22] W. Lew, M.C. Crowe, E. Karp, C.T. Campbell, J. Phys. Chem. C, 115 (2011) 9164-9170.

[23] T. Schiros, L.Å. Näslund, K. Andersson, J. Gyllenpalm, G.S. Karlberg, M. Odelius, H.

Ogasawara, L.G.M. Pettersson, A. Nilsson, J. Phys. Chem. C, 111 (2007) 15003-15012.

[24] M. Wakisaka, Y. Udagawa, H. Suzuki, H. Uchida, M. Watanabe, Energy Environ. Sci., 4 (2011) 1662-1666.

[25] H. Ogasawara, B. Brena, D. Nordlund, M. Nyberg, A. Pelmenschikov, L.G. Pettersson, A. Nilsson, Phys. Rev. Lett., 89 (2002) 276102.

[26] A. Baraldi, G. Comelli, S. Lizzit, M. Kiskinova, G. Paolucci, Surf. Sci. Rep., 49 (2003) 169-224.

[27] G. Pirug, C. Ritke, H.P. Bonzel, Surf. Sci., 241 (1991) 289-301.

[28] M.A. Henderson, Surf. Sci. Rep., 46 (2002) 1-308.

[29] A. Hodgson, S. Haq, Surf. Sci. Rep., 64 (2009) 381-451.

[30] M. Wakisaka, H. Suzuki, S. Mitsui, H. Uchida, M. Watanabe, Langmuir, 25 (2009) 1897-1900. 
[31] S. Axnanda, E.J. Crumlin, B. Mao, S. Rani, R. Chang, P.G. Karlsson, M.O.M. Edwards, M. Lundqvist, R. Moberg, P. Ross, Z. Hussain, Z. Liu, Scientific Reports, 5 (2015) 9788.

[32] M. Yoshida, H. Kondoh, The Chemical Record, 14 (2014) 806-818.

[33] K.A. Stoerzinger, W.T. Hong, E.J. Crumlin, H. Bluhm, Y. Shao-Horn, Acc. Chem. Res., 48 (2015) 2976-2983.

[34] A.K. Opitz, A. Nenning, C. Rameshan, R. Rameshan, R. Blume, M. Hävecker, A. Knop-Gericke, G. Rupprechter, J. Fleig, B. Klötzer, Angew. Chem., Int. Ed., 54 (2015) 2628-2632.

[35] S.T. Abrahami, T. Hauffman, J.M.M. de Kok, J.M.C. Mol, H. Terryn, J. Phys. Chem. C, 119 (2015) 19967-19975.

[36] C. Zhang, Y. Yu, M.E. Grass, C. Dejoie, W. Ding, K. Gaskell, N. Jabeen, Y.P. Hong, A. Shavorskiy, H. Bluhm, W.-X. Li, G.S. Jackson, Z. Hussain, Z. Liu, B.W. Eichhorn, J. Am. Chem. Soc., 135 (2013) 11572-11579.

[37] T. Ryo, K. Hiroshi, J. Phys.: Condens. Matter, 27 (2015) 083003.

[38] J.G. Wang, W.X. Li, M. Borg, J. Gustafson, A. Mikkelsen, T.M. Pedersen, E. Lundgren, J. Weissenrieder, J. Klikovits, M. Schmid, B. Hammer, J.N. Andersen, Phys. Rev. Lett., 95 (2005) 256102.

[39] W. Ji, Z.-Y. Lu, H. Gao, Phys. Rev. Lett., 97 (2006) 246101.

[40] W. Zhang, J. Yang, Y. Luo, S. Monti, V. Carravetta, J. Chem. Phys., 129 (2008) 064703-064708.

[41] Z.-H. Zeng, J.L.F. Da Silva, H.-Q. Deng, W.-X. Li, Phys. Rev. B, 79 (2009) 205413-205413.

[42] Z. Zeng, X. Ma, W. Ding, W. Li, Science China Chemistry, 53 (2010) 402-410.

[43] D.R. Butcher, M.E. Grass, Z. Zeng, F. Aksoy, H. Bluhm, W.-X. Li, B.S. Mun, G.A. Somorjai, Z. Liu, J. Am. Chem. Soc., 133 (2011) 20319-20325.

[44] L.O. Paz-Borbón, A. Hellman, H. Grönbeck, J. Phys. Chem. C, 116 (2012) 3545-3551.

[45] J.R. Boes, P. Kondratyuk, C. Yin, J.B. Miller, A.J. Gellman, J.R. Kitchin, Surf. Sci., 640 (2015) 127-132.

[46] J.M. Bray, J.L. Smith, W.F. Schneider, Top. Catal., 57 (2014) 89-105.

[47] G. Kresse, J. Hafner, Phys. Rev. B, 48 (1993) 13115-13118.

[48] G. Kresse, J. Furthmuller, Comput. Mater. Sci., 6 (1996) 15-50.

[49] P.E. Blochl, Phys. Rev. B, 50 (1994) 17953-17979.

[50] G. Kresse, D. Joubert, Phys. Rev. B, 59 (1999) 1758-1775.

[51] M. Marsman, G. Kresse, J. Chem. Phys., 125 (2006) 104101.

[52] J.P. Perdew, K. Burke, M. Ernzerhof, Phys. Rev. Lett., 77 (1996) 3865-3868.

[53] B. Hammer, L.B. Hansen, J.K. Nørskov, Phys. Rev. B, 59 (1999) 7413-7421.

[54] J. Klimes, D.R. Bowler, A. Michaelides, Phys. Rev. B, 83 (2011) 195131.

[55] J. Wellendorff, K.T. Lundgaard, A. Møgelhøj, V. Petzold, D.D. Landis, J.K. Nørskov, T. Bligaard, K.W. Jacobsen, Phys. Rev. B, 85 (2012) 235149.

[56] S.M. Jackson, V.M. Nield, R.W. Whitworth, M. Oguro, C.C. Wilson, J. Phys. Chem. B, 101 (1997) 6142-6145.

[57] Z. Raza, D. Alfe, C.G. Salzmann, J. Klimes, A. Michaelides, B. Slater, Phys. Chem. Chem. Phys., 13 (2011) 19788-19795.

[58] J.J. Mortensen, K. Kaasbjerg, S.L. Frederiksen, J.K. Nørskov, J.P. Sethna, K.W. Jacobsen, Phys. Rev. Lett., 95 (2005) 216401.

[59] J.J. Mortensen, L.B. Hansen, K.W. Jacobsen, Phys. Rev. B, 71 (2005) 035109.

[60] A.B. Alchagirov, J.P. Perdew, J.C. Boettger, R.C. Albers, C. Fiolhais, Phys. Rev. B, 67 (2003) 026103.

[61] F. Vincenzo, M. Methfessel, J. Phys.: Condens. Matter, 8 (1996) 6525.

[62] M. Mavrikakis, P. Stoltze, J.K. Nørskov, Catal. Lett., 64 (2000) 101-106.

[63] J.G. Wang, B. Hammer, J. Chem. Phys., 124 (2006) 184704. 
558 [64] Y. Ha, Z. Zeng, Y. Cohen, J. Greeley, A.A. Gewirth, J. Phys. Chem. C, 120 (2016) 8674-8683.

559 [65] L. Köhler, G. Kresse, Phys. Rev. B, 70 (2004) 165405.

560 [66] E. Whalley, J. Chem. Phys., 81 (1984) 4087-4092.

561 [67] Z. Zeng, M.E. Bjorketun, S. Ebbesen, M.B. Mogensen, J. Rossmeisl, Phys. Chem. Chem. Phys., 56215 (2013) 6769-6772.

563 [68] Z. Zeng, J. Greeley, Catal. Commun., 52 (2014) 78-83.

564 [69] J. Carrasco, B. Santra, J. Klimeš, A. Michaelides, Phys. Rev. Lett., 106 (2011) 026101.

565 [70] Z. Zeng, M.K.Y. Chan, Z.-J. Zhao, J. Kubal, D. Fan, J. Greeley, J. Phys. Chem. C, 119 (2015)

566 18177-18187.

567 [71] Z. Zeng, F. Calle-Vallejo, M.B. Mogensen, J. Rossmeisl, Phys. Chem. Chem. Phys., 15 (2013)

568 7526-7533.

569 [72] A. Clayborne, H.-J. Chun, R.B. Rankin, J. Greeley, Angew. Chem., Int. Ed., 54 (2015) 8255-

5708258.

571 [73] M. Peuckert, H.P. Bonzel, Surf. Sci., 145 (1984) 239-259.

572 [74] J. Herranz, J. Durst, E. Fabbri, A. Patru, X. Cheng, A.A. Permyakova, T.J. Schmidt, Nano

573 Energy, doi:10.1016/j.nanoen.2016.1001.1027.

574 [75] D. Strmcnik, K. Kodama, D. van der Vliet, J. Greeley, V.R. Stamenkovic, N.M. Marković, Nat.

575 Chem., 1 (2009) 466-472.

576 [76] V.R. Stamenkovic, B. Fowler, B.S. Mun, G.F. Wang, P.N. Ross, C.A. Lucas, N.M. Markovic, 577 Science, 315 (2007) 493-497.

578 [77] V. Stamenkovic, B.S. Mun, K.J.J. Mayrhofer, P.N. Ross, N.M. Markovic, J. Rossmeisl, J.

579 Greeley, J.K. Nørskov, Angew. Chem.-Int. Edit., 45 (2006) 2897-2901.

580

581 

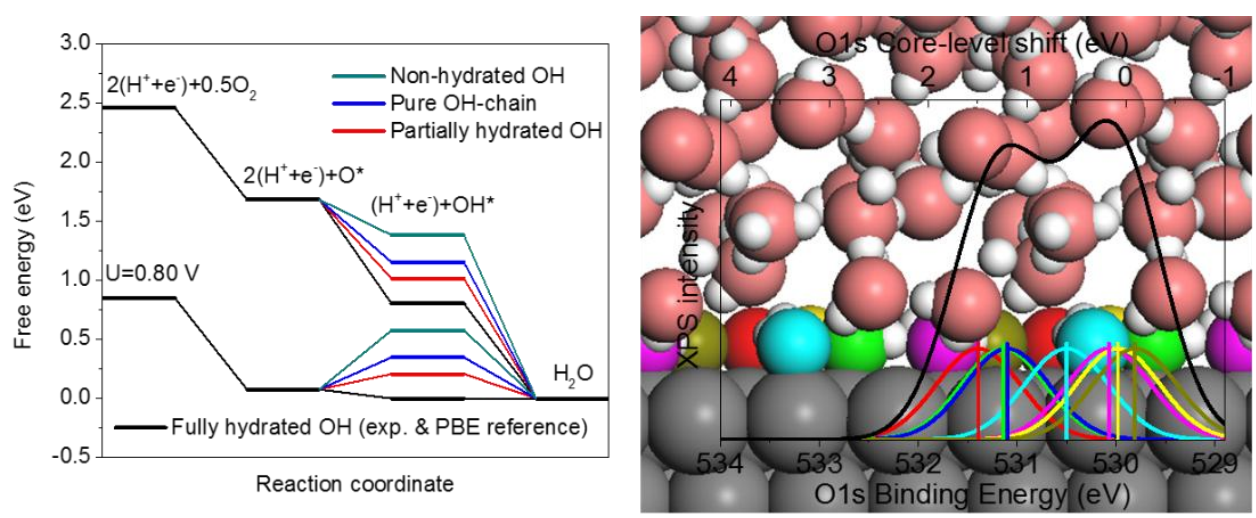

583 